\title{
Impacto psicológico del Covid-19 en la población Manabita
}

\section{Psychological impact of Covid-19 on the Manabita population}

Impacto psicológico del Covid-19

Ariagna Martínez Pérez ${ }^{(1)}$

Yelennis Galardy Domínguez ${ }^{(2)}$

Roberth Olmedo Zambrano Santos ${ }^{(3)}$

Roberth Patricio Zambrano Ubillus ${ }^{(4)}$

(1) Universidad Estatal del Sur de Manabí. Jipijapa. Ecuador. email: ariagna.martinez@unesum.edu.ec.

ORCID: https://orcid.org/0000-0003-1710-4079.

(2) Universidad Estatal del Sur de Manabí. Jipijapa. Ecuador. email: galardy.yelennis@unesum.edu.ec.

ORCID: https://orcid.org/0000-0002-6394-5584

(3) Universidad Estatal del Sur de Manabí / Instituto Superior Tecnológico Portoviejo. Ecuador. robert.zambrano@unesum.edu.ec. ORCID: https://orcid.org/0000-0002-4072-4738

(4) Universidad de Especialidades Espíritu Santo. Guayaquil. Ecuador. rpzambrano@uees.edu.ec. ORCID: https://orcid.org/0000-0002-7526-4938

Contacto: ariagna.martinez@unesum.edu.ec

Recibido: 9-9-2020

Aprobado: 5-12-2020 


\title{
Resumen
}

La investigación es descriptiva, no experimental, transversal, con el propósito de determinar el impacto psicológico del Covid-19 en la población de Manabí, Ecuador, en el período de abril a mayo de 2020. Para la obtención de los datos se aplicó una encuesta en línea a 2261 individuos mayores de 15 años de edad y procesados en el software SPSS 25. Identificándose que el grupo de edad predominante en el estudio fue el de 35-49 años, el mayor número de encuestados fueron del sexo femenino y del estatus estudiante. Los síntomas que aparecieron con mayor frecuencia fueron estrés, insomnio y tristeza, con presencia de estados psicológicos patológicos y normales, reflejados en comportamientos estresados y amigables. Detectando además que a pesar de tener una preparación psicológica familiar que varió de regular a buena, los individuos refirieron presentar daños psicológicos ante la imposición de la cuarentena y el aislamiento social, sintiéndose preocupados y temerosos. Las fuentes que aportaron la mayor cantidad de información sobre la enfermedad y su repercusión fueron la televisión y las redes sociales.

Palabras claves: Coronavirus, salud mental, estrés, daño psicológico

\begin{abstract}
The research is descriptive, not experimental, cross-sectional, with the purpose of determining the psychological impact of COVID-19 in the population of Manabí, Ecuador, in the period from April to May 2020. To obtain the data, a survey was applied 2261 individuals over 15 years of age online and processed in the SPSS 25 software. Identifying that the predominant age group in the study was 35-49 years, the largest number of respondents were female and student status. The symptoms that appeared most frequently were stress, insomnia and sadness, with the presence of pathological and normal
\end{abstract}


psychological states, reflected in stressed and friendly behaviors. Also detecting that despite having a family psychological preparation that ranged from fair to good, the individuals reported presenting psychological damage due to the imposition of quarantine and social isolation, feeling worried and fearful. The sources that provided the most information on the disease and its impact were television and social networks.

Keywords: Coronavirus, mental health, stress, psychological damage

\section{Introducción}

Los coronavirus son una amplia familia de virus, algunos tienen la capacidad de transmitirse de los animales a las personas. Producen cuadros clínicos que van desde el resfriado común hasta enfermedades más graves. (Ministerio de Salud Pública del Ecuador, 2020)

Este nuevo coronavirus tiene distintas denominaciones: 2019-nCoV según la OMS y SARS-CoV-2 según el Comité Internacional de Taxonomía de Virus. La enfermedad que lo causa se ha denominado 2019-nCoV1 (Palacios et al., 2020).

La Covid-19 es un síndrome clínico con espectro amplio de severidad, que varía desde síntomas sutiles hasta una neumonía severa, shock séptico o enfermedad sistémica inflamatoria. Se han descrito múltiples síntomas asociados a SARS CoV-2, siendo fiebre, tos, disgeusia/hiposmia, disnea y fatiga los síntomas más frecuentes (Madrigal, Quesada, \& García, 2020).

Los primeros casos sospechosos fueron anunciados oficialmente por la Organización Mundial de la Salud el 31 de diciembre de 2019, tras la aparición de este nuevo coronavirus unas tres semanas antes en uno de los mercados de la región china de Wuhan, de donde adquirió su nombre. 
China, país en el que se encuentra el epicentro del brote en Asia, ha confirmado hasta el momento más de 85.066 casos de COVID-19. Sin embargo, ya no encabeza la clasificación tras ser superado por Estados Unidos, con alrededor de 6 millones de positivos confirmados. Por su parte, Francia fue el primer país europeo afectado y hasta la fecha se han detectado un total de 293 mil casos de este virus, también conocido como la neumonía de Wuhan. Ahora bien, no es el único país del Viejo Continente al que ha llegado el brote. De hecho, 57 países europeos han registrado hasta el momento infectados entre sus ciudadanos, con mayor prevalencia, España, Rusia, Reino Unido, Italia y Alemania (Orús, 2020).

Hasta el 27 de agosto de 2020, un total de 6.922.174 casos de COVID-19 han sido registrados en América Latina y el Caribe. Brasil es el país más afectado por esta pandemia en la región, con más de 3,7 millones de casos confirmados. Perú se ubica en segundo lugar, con más de 607 mil infectados. México, por su parte, ha registrado un total de 574 mil casos. Dentro de los países más afectados por el nuevo tipo de coronavirus en América Latina también se encuentran Ecuador, Chile, Argentina, República Dominicana y Colombia (Ríos, 2020).

En Ecuador, el Instituto Nacional de Investigación en Salud Pública (INSPI) ha tomado 328.929 muestras, de las cuales 113.767 son positivas para COVID-19. Las provincias más afectadas son Pichincha con 23.898, Guayas con 18.836 y Manabí con 8.482 casos (Ministerio de Salud Pública del Ecuador, 2020).

Inicialmente el brote del SARS-CoV-2 en China causó alarma y estrés en la población general. El miedo a la enfermedad se podría explicar por la novedad e incertidumbre que genera. El creciente número de pacientes y casos sospechosos suscitaron la preocupación del público por infectarse. El miedo se exacerbó por los mitos y por la desinformación en las redes sociales y medios de comunicación, a menudo impulsado por noticias erróneas y por la mala comprensión de los mensajes 
relacionados al cuidado de la salud. Luego de la declaración de emergencia en China, un estudio reveló un incremento de las emociones negativas (ansiedad, depresión e indignación) y una disminución de las emociones positivas (felicidad y satisfacción). Esto generó un comportamiento errático entre las personas, lo cual es un fenómeno común, ya que existe mucha especulación sobre el modo y la velocidad de trasmisión de la enfermedad, actualmente, sin un tratamiento definitivo. Además, la cuarentena incrementa la posibilidad de problemas psicológicos y mentales, principalmente por el distanciamiento entre las personas. En ausencia de comunicación interpersonal, es más probable que los trastornos depresivos y ansiosos ocurran o empeoren. Por otro lado, la cuarentena reduce la disponibilidad de intervenciones psicosociales oportunas y de asesoramiento psicoterapéutico de rutina. (Huarcaya-Victoria, 2020)

La Organización Mundial de la Salud (OMS) subrayó que la amenaza del COVID-19 y el confinamiento están causando un fuerte impacto psicológico en las sociedades, que debe atenderse con "medidas imaginativas". El aislamiento, el distanciamiento físico, el cierre de escuelas y lugares de trabajo son desafíos que afectan, y es natural sentir estrés, ansiedad, miedo y soledad en estos momentos. Se daba la alerta sobre el inminente impacto psicológico (a corto, mediano y largo plazo) de la COVID-19, reflejado en manifestaciones clínicas psicológicas alrededor de los posibles trastornos relacionados con traumas y factores de estrés en su fase aguda, lo cual no debe ser ignorado en la sociedad.

Sin embargo, hasta ahora, la atención de salud mental a los pacientes y profesionales de la salud afectados por la epidemia de COVID-19 ha sido subestimada. El primer impacto de la epidemia es la crisis misma. Los pacientes relacionados con infección por SARS-CoV-2, sean casos confirmados o sospechosos, pueden experimentar temor a presentar una infección con un nuevo virus potencialmente 
mortal, y aquellos que se hallan en cuarentena pueden experimentar aburrimiento, soledad e ira. Además, los síntomas de la infección y la tos, así como los efectos adversos del tratamiento, podrían provocar un empeoramiento de la ansiedad y la angustia mental. Relacionar este virus con la muerte es en gran parte la causa. Entonces, entre sus principales manifestaciones clínico-psicológicas destacan también a la hipocondriasis, el insomnio, los temores, o incluso crisis de ansiedad generalizada y de pánico. Estos síntomas son compatibles a los que se observan en el síndrome del estrés post traumático (Ruiz, Díaz, \& Zaldívar 2020).

El mundo pospandemia no será igual al que vivimos hasta el 2019 y los investigadores tienen el compromiso de participar en la construcción de este nuevo futuro, donde prime el equilibrio entre las esferas biológica, psicológica y social, y la relación del hombre con el medio ambiente que lo rodea, garantizando la salud, siendo el pilar que le confiere un valor agregado a esta investigación.

El presente artículo tiene por objetivo determinar el impacto psicológico del Covid-19 en la población manabita, Ecuador.

\section{Materiales y métodos}

Se realizó un estudio descriptivo, no experimental, transversal, en el período de abril a mayo de 2020, mediante la aplicación de una encuesta en línea, a 2261 individuos mayores de 15 años de edad, de la provincia Manabí, Ecuador.

La información obtenida fue procesada con el software SPSS 25, que permitió obtener los datos necesarios para la ejecución de la investigación, con el objetivo de determinar el impacto psicológico del Covid-19 en la población manabita. Señalar que los autores declaran no tener conflictos de intereses. 


\section{Resultados}

En la tabla1 se aprecia que el grupo de edad predominante en el estudio es el 35-49 años, seguido por los gruposde 20-24 años y de 50-59 años, con 29.7\%, 22.8\% y $11.8 \%$ respectivamente.

\begin{tabular}{|l|l|l|}
\hline Grupos de edades & Frecuencia & Porcentaje \\
\hline $15-19$ años & 240 & 10.6 \\
\hline $20-24$ años & 516 & 22.8 \\
\hline $25-29$ años & 249 & 11.0 \\
\hline $30-34$ años & 238 & 10.5 \\
\hline $35-49$ años & 671 & 29.7 \\
\hline $50-59$ años & 267 & 11.8 \\
\hline $60+$ años & 80 & 3.5 \\
\hline Total & 2261 & 100 \\
\hline
\end{tabular}

Tabla 1. Distribución por grupos de edades

En el análisis relacionado con la distribución del sexo, se muestra en la tabla 2, que el mayor número de personas encuestadas corresponde al sexo femenino, con 1467, que representa el $64,9 \%$ del total.

\begin{tabular}{|l|l|l|}
\hline Sexo & Frecuencia & Porcentaje \\
\hline Femenino & 1467 & 64,9 \\
\hline Masculino & 794 & 35,1 \\
\hline Total & 2261 & 100 \\
\hline
\end{tabular}

Tabla 2. Distribución según sexo

En lo concerniente a la distribución de la población según el estatus social, siendo los estudiantes el grupo con mayor incidencia, representado 762 individuos $(33,7 \%)$, seguidos por los trabajadores, con $620(27,4 \%)$. Se muestran los resultados en la tabla 3.

La información presenta que en lo relacionado a los síntomas de afectación psicológica, en la tabla 4 se observan los síntomas que aparecieron con mayor frecuencia en la población objeto de estudio, 
siendo los más representativos el estrés con 1173 personas (51.9\%), seguido por el insomnio con 869 (38.4\%) y la tristeza con $795(35.2 \%)$.

\begin{tabular}{|l|l|l|}
\hline Estatus social & Frecuencia & Porcentaje \\
\hline Ama de casa & 5 & 0.2 \\
\hline Estudiante & 762 & 33.7 \\
\hline Desempleado & 407 & 18.0 \\
\hline Trabajador Público & 620 & 27.4 \\
\hline Trabajador Privado & 326 & 14.4 \\
\hline Jubilado & 48 & 2.1 \\
\hline Otros & 93 & 4.1 \\
\hline Total & 2261 & 100 \\
\hline
\end{tabular}

Tabla 3. Distribución según estatus social

\begin{tabular}{|l|l|l|}
\hline Síntomas & Frecuencia & Porcentaje \\
\hline Estrés & 1173 & 51,9 \\
\hline Tristeza & 795 & 35,2 \\
\hline Insomnio & 869 & 38,4 \\
\hline Ansiedad & 789 & 34,9 \\
\hline Depresión & 416 & 18,4 \\
\hline Ninguno & 28 & 1,2 \\
\hline Otros & 26 & 1,1 \\
\hline Total & 4096 & 100 \\
\hline
\end{tabular}

Tabla 4. Síntomas de afectación psicológica

En la tabla 5, se muestra los estados psicológicos que presentaron los miembros de la familia relacionados con la pandemia, donde 992 individuos se comportaron estresados representando el 43,9\% de los encuestados, mientras que 887 se manifestaron amigables $(39,2 \%)$, demostrando la variabilidad de estados que ocasionan los eventos inusitados.

\begin{tabular}{|l|l|l|}
\hline Estados psicológicos & Frecuencia & Porcentaje \\
\hline Ansiosos & 639 & 28,3 \\
\hline Estresados & 992 & 43,9 \\
\hline Iritados & 373 & 16,5 \\
\hline Aburridos & 797 & 35,2 \\
\hline Amigables & 887 & 39,2 \\
\hline Total & 3688 & 100 \\
\hline
\end{tabular}


Tabla 5. Estados psicológicos de los miembros de la familia

En la tabla 6 los reflejan los niveles de preparación psicológica demostrado por las familias manabitas, siendo regular en el 65,5\% (1481) y bueno en el 24,6\% (557), lo que les facilitará la ejecución de acciones para preservar la salud de los miembros.

\begin{tabular}{|l|l|l|}
\hline $\begin{array}{l}\text { Niveles de } \\
\text { preparación }\end{array}$ & Frecuencia & Porcentaje \\
\hline Bueno & 557 & 24,6 \\
\hline Regular & 1481 & 65,5 \\
\hline Malo & 223 & 9,9 \\
\hline Total & 2261 & 100 \\
\hline
\end{tabular}

Tabla 6. Niveles de preparación psicológica de las familias ante la pandemia

En la tabla 7, se valoran los daños psicológicos causados por el aislamiento, donde 921 pers $(40,7 \%)$ refirieron sentirse afectadas, mientras que $880(38,9 \%)$ no pudieron precisar la repercusión que les ha generado esta situación.

\begin{tabular}{|l|l|l|}
\hline Daños psicológicos & Frecuencia & Porcentaje \\
\hline Sí & 921 & 40,7 \\
\hline No & 460 & 20,3 \\
\hline Tal vez & 880 & 38,9 \\
\hline Total & 2261 & 100 \\
\hline
\end{tabular}

Tabla 7. Daños psicológicos causados por el aislamiento social

La tabla 8, se refleja que los encuestados se sintieron preocupados y temerosos ante la imposición de la cuarentena, representando el 79,5\% y el 30,3\% respectivamente.

\begin{tabular}{|l|l|l|}
\hline Estados emocionales & Frecuencia & Porcentaje \\
\hline Preocupación & 1797 & 79,5 \\
\hline Temor & 686 & 30,3 \\
\hline Angustia & 539 & 23,8 \\
\hline Ansiedad & 405 & 17,9 \\
\hline Total & 3427 & 100 \\
\hline
\end{tabular}

Tabla 8. Estados emocionales causados por la imposición de la cuarentena 
En la tabla 9 se aprecia que las principales fuentes que los encuestados recibieron información fueron la televisión con 1187, que representó el 52,5\%, seguido de las redes sociales con 931 (41,2\%).

\begin{tabular}{|l|l|l|}
\hline Fuentes de información & Frecuencia & Porcentaje \\
\hline Televisión & 1187 & 52,5 \\
\hline Radio & 67 & 3,0 \\
\hline Periódico & 41 & 1,8 \\
\hline Celular & 20 & 0,9 \\
\hline Redes sociales & 931 & 41,2 \\
\hline Otros & 15 & 0,7 \\
\hline TOTAL & 2261 & 100 \\
\hline
\end{tabular}

Tabla 9. Fuentes de información de la enfermedad

\section{Discusión}

Los resultados antes expuestos reflejan que en la población objeto de estudio predominaron los grupos de edades de 35-49 años, y el mayor número de encuestados fueron del sexo femenino, y del estado estudiante, en correspondencia con una investigación realizada en China, que fue el primer país afectado y con un elevado número de casos positivos. (Lozano-Vargas, 2020)

Debido a lo reciente de la enfermedad por coronavirus se cuenta con poca evidencia disponible, sin embargo, en esta investigación se reportan una serie de reacciones y estados psicológicos. Como síntomas de afectación psicológica se señalan el estrés, el insomnio y la tristeza, dando al traste con estados emocionales que variaron desde estresados a amigables, en concordancia con una investigación española, que considera a la pandemia por coronavirus como situación amenazadora, que produce cambios adaptativos emocionalmente, provocando que los individuos no se comporten de manera habitual (Ruiz, Díaz, \& Zaldívar, 2020).

A pesar que las personas encuestadas manifestaron que sus familias tenían niveles de preparación entre regular y bueno, el aislamiento social y la imposición de la cuarentena causaron daños psicológicos y 
estados emocionales caracterizados por preocupación, temor y angustia. Aún cuando la cuarentena se ha utilizado como estrategia de salud pública para reducir la transmisión de enfermedades, estas condiciones están asociadas con desafíos psicológicos para aquellos implicados, sus seres queridos, incluso para los trabajadores de la salud que los cuidan, en este se concuerda con (Cantero, 2020; Torralva, 2020).

Se reportó que existirían diversos factores que incidirían en la respuesta de las personas al distanciamiento social, como por ejemplo el tiempo de duración de la cuarentena, temores de infección, frustración, aburrimiento, suministros inadecuados, información inadecuada, pérdidas financieras y estigma (Urzúa et al., 2020).

Las principales fuentes que los encuestados recibieron información sobre la enfermedad por coronavirus fueron la televisión y las redes sociales. En la práctica se conoce que en los medios de difusión se comparte información no verificada, que se expande rápidamente y puede generar alteraciones psicológicas, si no se usa de forma adecuada y racional.

Al respecto, la Organización Mundial de la Salud (OMS), lanzó una nueva plataforma de información llamada Red de Información de la OMS para Epidemias EPI-WIN3, que tiene como objetivo garantizar la veracidad de la información oficial comunicada al público a través del intercambio con profesionales que emiten recomendaciones y a su vez reciben información sobre la COVID-19 (Urzúa et al., 2020).

\section{Conclusiones}

En el estudio se identificó que el grupo de edad predominante fue el de 35-49 años, el mayor número de encuestados fueron del sexo femenino y del estatus estudiante. Los síntomas que aparecieron con mayor frecuencia en la población objeto de estudio fueron estrés, insomnio y tristeza; determinándose 
estados psicológicos patológicos y normales en los miembros de la familia, que lo reflejaron en comportamientos estresados y amigables.

Se identificó además que a pesar de tener una preparación psicológica familiar que varió de regular a buena, los individuos refirieron presentar daños psicológicos ante la imposición de la cuarentena y el aislamiento social, sintiéndose preocupados y temerosos.

Se constató que los encuestados recibieron información sobre la enfermedad mediante la televisión y las redes sociales, lo que juega un papel fundamental en el comportamiento humano, debido a la sobreabundancia de información falsa y a su rápida propagación entre las personas y medios.

\section{Bibliografía}

Alfonso, I. \& Fernández, M. (2020). Comportamiento informacional, infodemia y desinformación durante la pandemia de COVID-19. Revista Anales de la Academia de Ciencias de Cuba, 10, (2). Recuperado de: http://www.revistaccuba.cu/index.php/revacc/rt/printerFriendly/882/888

Cantero, M. (2020). Las estadísticas sanitarias y la invisibilidad por sexo y de género durante la epidemia de COVID-19. Gaceta Sanitaria, 3. Recuperado de: https://doi.org/10.1016/j.gaceta.2020.04.008

Huarcaya-Victoria, J. (2020). Consideraciones sobre la salud mental. Revista Peruana de Medicina $\begin{array}{llllll}\text { Experimental } & \mathrm{y} & \text { Salud } & \text { Pública, } & \text { (2) } & \text { Recuperado de: }\end{array}$ https://doi.org/10.17843/rpmesp.2020.372.5419 
Lozano-Vargas, A. (2020). Impacto de la epidemia del Coronavirus (COVID-19) en la salud mental del personal de salud y en la población general de China. Revista de Neuropsiquiatría. 83, (1). Recuperado de: $\underline{\text { http://dx.doi.org/10.20453/rnp.v83i1.3687 }}$

Madrigal, D., Quesada, M. \& García, M. (2020). SARS CoV-2. Manifestaciones clínicas y consideraciones en el abordaje diagnóstico de COVID- 19. Revista Médica de Costa Rica15,(16). Recuperado de: http://revistamedicacr.com/index.php/rmcr/article/view/287

Ministerio de Salud Pública del Ecuador.(2020). Actualización de casos de Coronavirus en Ecuador Recuperado de https://www.salud.gob.ec/actualizacion-de-casos-decoronavirus-en-ecuador/

Orús, A. (2020). COVID-30: Países afectados según los casos confirmados de contagio 2020. Recuperado de: https://es.statista.com/estadisticas/1091192/paises-afectados-por-el-coronavirusde-wuhan-segun-los-casos-confirmados/

Palacios, M., Santos, M.; Velázquez, M., \& León, M. (2020). COVID-19, una emergencia de salud pública mundial. Revista Clínica Española. Recuperado de: https://doi.org/10.1016/j.rce.2020.03.001

Ríos, A. (2020). Número de casos confirmados de coronavirus (COVID-19) en América Latina y el Caribe por país 2020. Recuperado de https://es.statista.com/estadisticas/1105121/numero-casoscovid-19-america-latina-caribe-pais/

Ruiz, A., Díaz, K. \& Zaldívar, D. (2020). La psicología como ciencia en el afrontamiento a la COVID19. Revista Ciencias sociales y humanísticas, 2,(3).Recuperado de: http://www.revistaccuba.sld.cu/index.php/revacc/article/view/839/855 
Revista Sinapsis. Vol 3, $N^{r o} 18$, diciembre de 2020 | ISSN 1390-9770

Torralva, D. T. (2020). Fundación INECO. Obtenido de Fundación INECO. Recuperado de: www.fundacionineco.org/

Urzúa, A., Vera, P., Caqueo, A., \& Polanco, P. (2020). La Psicología en la prevención y manejo del COVID-19. Aportes desde la evidencia inicial. Revista Terapia Psicológica, 38, (1), 103-118. Recuperado de: https://scielo.conicyt.cl/pdf/terpsicol/v38n1/0718-4808-terpsicol-38-01-0103.pdf 